\title{
Teaching sustainability as a contested concept: Capitalizing on variation in engineering educators' conceptions of environmental, social and economic sustainability
}

Authors: A L Carew and C A Mitchell

Author affiliations:

Dr A L Carew*

Centre for Educational Development and Interactive Resources

University of Wollongong

NSW 2522 Australia

Phone: +61242215012

Fax: +61 242258312

Email: carew@uow.edu.au

Associate Professor C A Mitchell

Institute for Sustainable Futures

University of Technology, Sydney

NSW 2007 Australia

Phone: + 61295144953

Fax: +6129514 4941

Email: Cynthia.Mitchell@uts.edu.au

* corresponding author 


\section{Abstract}

This study documents variation in engineering academics conceptions of sustainability. We investigated how a group of Australian engineering academics described environmental, social and economic sustainability, and identified a broad range of actions that participating academics associated with achieving sustainability. The study suggested marked variation in the actions that participating academics viewed as coherent with sustainable engineering practice, and therefore potentially marked variations in the sustainability actions academics might advocate to their undergraduate students. Rather than framing this variation as problematic for teaching and learning sustainable engineering, we suggest that such variation in conception of sustainability, and explicit contestation of this variation in the engineering classroom, offers opportunities to enrich undergraduate sustainability learning and teaching. We develop this argument by using some generic environmental, economic, and social theoretical frameworks to characterize the differences according to the values and assumptions that may underpin the observed variation. Validated frameworks are useful to move beyond discussions based on 'opinion', because they provide a framework for critical reflection by engineering

students and academics about the values and assumptions that inform engineering practice generally and sustainable engineering practice, particularly.

\section{Keywords}

sustainability, engineering, academics, teaching, learning, undergraduate 


\section{Introduction}

\subsection{Impetus to infuse undergraduate education with sustainability}

The past decade has witnessed international interest in incorporating the skills, attitudes and concepts of sustainability into undergraduate university courses across a range of disciplines [1]. This interest in equipping graduates to enact sustainability is impacting on the engineering education context. The traditional role of the engineer in the design and application of technology for the resolution of problems has resulted in the profession coming under pressure from government, industry and society to practice engineering more sustainably. This is because the role of technology provider has placed engineering professionals in a pivotal position in structuring the way societies function. Harding [2] pointed out that while society drives the hunt for new technologies and applications by identifying and defining problems for engineers to solve, the range of technological solutions generated by engineers in response to those problems plays a fundamental role in structuring the urban environment, and to some extent delineates the different ways in which societies might use natural resources and waste sinks in the pursuit of economic gain and improved outcomes for humanity.

In the Australian context, pressure for more sustainable engineering has driven the body that accredits undergraduate engineering courses to specify sustainability competence as a condition of graduation. In 2000, Engineers, Australia implemented an accreditation process that mandated that academics must ensure that students understand sustainability by the time of graduation [3]. This effort at reorienting the education and induction of 
new engineers to incorporate sustainability competence has meant that many Australian engineering academics face the responsibility and challenge of assisting undergraduate students to an understanding of what sustainable engineering is and how it might be practiced. This would be a reasonably straightforward task if there were uniform agreement about what sustainability is and what its implementation in engineering professional practice entailed. Sustainability is, however, a contested concept.

\subsection{Sustainability as a contested concept}

Walter Filho, editor of the International Journal of Sustainability in Higher Education, has said "...what does sustainable development really mean? Depending on the way it is looked at, it may have many meanings" ([4] p. 9). The literature on sustainability is replete with anecdotal and empirical evidence of variation in the way that both sustainability experts and lay persons conceive of or understand the general concept [1] [4] [5] [6] [7] [8] [9] [10]. Much of the debate in the literature takes the form of philosophical arguments in favour of a particular definition, understanding or application of sustainability: the presumed intention being to converge on one or two singular, generic or definitive conceptions of sustainability. We hold, however, that sustainability is a defensibly and necessarily variable concept.

The existence of different conceptions of sustainability is not surprising because the concept is comparatively young, complex and abstract and, as we and others have discussed [8] [11], it rests on both factual and ethical components. As such, different underpinning value-based assumptions would naturally contribute to variation in the way that sustainability is understood and explained. Further, debates about sustainability are 
often centred on complex or poorly understood systems [12]. Being partly value-based and focused on complex systems means that the conceptual contest about sustainability is both inevitable and healthy, and offers a means to give voice to different stakeholder perspectives, to further evolve the concept, and supports the continuing flexible application of sustainability in contextualised consultative decision-making [1] [5]. Crofton has also suggested that the conceptual debate about sustainability opens up the a range of starting points and ending points which sustainable decision processes may work from and towards [13] [14]. As such, attempts to 'normalise', closely define, or freeze sustainability into a constant, inflexible, singular or generic concept may be somewhat counterproductive to the implementation of sustainability. In short, debate about the nature of sustainability provides a means of maintaining the concept's flexibility to adapt to unique problem contexts, and its capacity to represent a range of different stakeholder perspectives.

\subsection{Variation in sustainability conception and teaching sustainable engineering}

The contest in the broader sustainability literature over what sustainability might entail manifests in distinctive ways in the engineering education literature. In an earlier paper we reviewed the engineering education literature and derived and discussed sustainability principles for the engineering education context [11]. We concluded that the general destination in terms of what a sustainable future (outcome) looked like was broadly agreed amongst the authors whose work we reviewed, but that the ways in which they believed we might achieve the specified outcomes (actions) were contested. This contest 
resulted in different prescriptions for sustainable engineering, for example, one author advocated pollution prevention as the path to more sustainable engineering outcomes [15] while another argued in favour of community engagement in decision processes [16]. The contest in the engineering education literature over what sustainability might entail suggested that while engineering academics were likely to agree at the level of principles, individual academics held varying conceptions of how sustainability might be achieved. So, while there may be broad agreement in the engineering academy about what sustainable outcomes look like, the literature suggests that engineering academics feel that sustainability requires differing actions.

Variation in the actions that individual academics associate with sustainable engineering has significance for both how and what engineering educators teach as sustainable engineering. Constructivist educational research suggests what a teacher already knows, thinks and feels about a topic will influence the way in which the teacher structures teaching and learning activities for students [17]. This theoretical position would suggest that what engineering academics already know, think and feel about sustainability will influence how and what they teach their undergraduate students about this concept. The foregoing argument held that engineering academics tended to diverge on the actions they believed that the implementation of sustainability warrants. This would suggest that what engineering academics already know, think and feel about sustainability would influence their approach to teach engineering students how to incorporate and enact sustainability in their work as professional engineers. This theoretical position is supported by evidence from the literature of substantial variation in the way that engineering 
academics construct and deliver engineering courses focused on sustainability. The proceedings of the 2002 Delft conference on Sustainability in Engineering contain over 70 papers describing approaches to teach sustainability in an engineering context, and the approaches described vary substantially. For example, Lemkowitz al. [18] described a schema for developing students' moral and intellectual criticality, whereas Wells' [19] course was more focused on sustainable plant design. The theoretical relationship between approach to teaching and prior conceptions of topic, and this evidence of variation in engineering academics' approaches to teaching sustainability suggest that inquiring into engineering academics' perceptions of sustainability beyond a given vision or set of principles could give us insights into the range of specific actions for sustainability that engineering academics might advocate to their students.

The next part of this paper reports on a study which mapped the range of qualitatively different ways that a group of Australian engineering academics conceived of environmental, social and economic sustainability.

The aims of the study were to:

- Engage the participating engineering academics in clarifying and making explicit their individual conceptions of environmental, social and economic sustainability;

- Encourage the participants to derive themes which represented the variation in conceptions of environmental, social and economic sustainability held by the group; and 
- Create an opportunity to speculate on the actions for sustainability and assumptions embodied in each theme.

\section{Methods and Results}

\subsection{Rendering sustainability conceptually accessible}

To investigate the detail of engineering academics' conceptions of sustainability, we needed to render the broad concept of sustainability more conceptually accessible to the academics who would participate in this study. To do this, we subdivided sustainability into three subordinate concepts: environmental, social and economic sustainability. This decision was initially based on the way that sustainability is presented and discussed in much of the literature on sustainable engineering, but was reinforced by an early experience of the context within which we were researching. In the following paragraphs, we expand on these two related reasons for subdividing the concept, sustainability.

Our initial reason for breaking down sustainability into three aspects of environmental, social and economic was that this subdivision of the ordinate concept is reasonably common in the literature. The general concept, sustainability is often introduced in the literature using Brundtland Statement: 
"Humanity has the ability to make development sustainable - to ensure that it meets the needs of the present without compromising the ability of future generations to meet their own needs." [20]

The Bruntland Statement was crafted during the World Congress on Environment and Development in 1987 and is a necessarily broad and decontextualised starting point. It provides inspiration but gives little guidance on what sustainability might mean or require. Many sustainability commentators and researchers expand Brundtland vision by describing sustainability in terms of three subordinate concepts. These three concepts are described using a range of different terms (eg. [21] [22]), which most simply translate to 'environment', 'society' and 'economy'. Various models or diagrams are used to illustrate the way that these three sub-systems relate to each other. One depiction comes from Mitchell [22] who has represented the three sub-systems as concentric and progressively nested. In Mitchell's depiction, the environmental system represented the ultimate limit, the socio-systems sat within the environmental system, and the economic system was depicted as a sub-system of the socio-system. In contrast, Clift [21] and many others have illustrated the interaction between the three sub-systems using an intersecting Venn diagram, with the central zone of overlap representing concurrent environmental, social and economic sustainability (Error! Reference source not found.). These depictions and descriptions supported the idea that the broad concept, sustainability could be rendered more accessible through subdivision into three interrelated subordinate concepts: environmental sustainability, social sustainability and economic sustainability. 


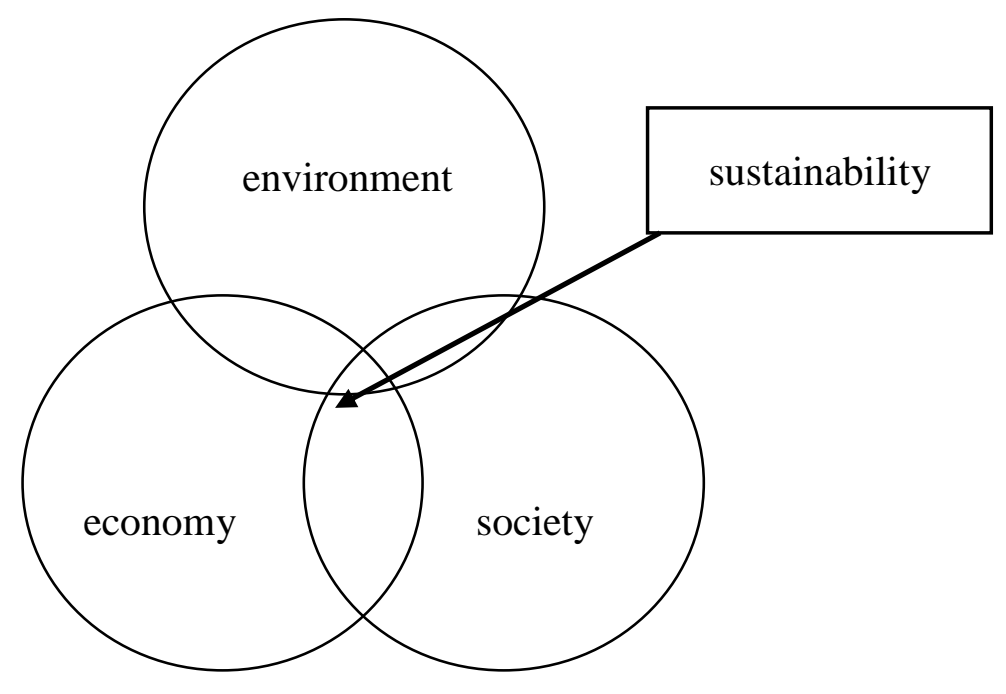

Figure 1. Sustainability in terms of three subordinate concepts: environment, society and economy (after [21]).

Our second reason for breaking down sustainability into three subordinate concepts was based on observations made during an earlier study in which we conducted interviews with engineering academics and asked them what they meant by 'sustainability' (results published as in Ref [23]). During this study we used secondary questions about what the participating academics meant by environmental, social and economic sustainability. The questions about environmental, social and economic sustainability were primarily included in the interview study as mechanisms to keep the interviewees on the topic of sustainability and as a means of re-invigorating interviews that stalled. Interestingly, we found that the participants tended to answer the question on what they meant by sustainability in very broad terms whereas, they tended to respond to the more specific 
questions about environmental, social and economic sustainability by describing specific actions or outcomes for sustainability.

So, the sustainability literature supported the subdivision of the broad concept sustainability into the sub-ordinate inter-related concepts environmental, social and economic sustainability, and our observations during our earlier interview study [23] suggested that this subdivision offered a means for investigating engineering academics' conceptions of sustainability in more depth.

\subsection{Data gathering}

The study was undertaken during a professional development workshop devised and facilitated by Associate Professor Cynthia Mitchell and Dr Anna Carew for the Australasian Association for Engineering Education's 13th Annual Conference (AaeE, September 2002, Canberra, Australia). The workshop was entitled 'Conceptions of Sustainability: Mapping the Territory' and attracted twenty three participants representing twelve Australian engineering faculties. All of the workshop participants were delegates to the AaeE conference and were actively engaged in teaching engineering at undergraduate level A a few had specific interest in or carriage of courses which dealt directly with the concept of sustainability.

During the workshop we asked participating academics to respond in writing to the questions:

'What do you mean by environmental sustainability?' 
'What do you mean by social sustainability?'

'What do you mean by economic sustainability?'

We employed an affinity process to facilitate the generation and thematic grouping of ideas [24]. This process is particularly effective for developing shared understanding around complex issues, for capturing a wide range of ideas, and enabling creative and divergent thinking. We employed this approach to provide participants with a cooperative means of engaging with the viewpoints of others that would be more reflective and potentially less combative than verbal discussion and debate.

According with the affinity process, participants were asked to transpose their answers in short form onto sticky Post-It® notes and to limit themselves to one idea per Post-It@. Participants could contribute as many or as few answers as they wished. We then asked the workshop participants to refrain from speaking and to group their Post-it ${ }^{\circledR}$ notes by theme on blank sheets of butcher's paper that were hanging on the walls of the workshop room.

Completing the affinity process, one of the workshop facilitators (Cynthia Mitchell) led a loose coalition of participants in attempting to name the resulting groups by their central theme. There were twelve themes identified although, as would be anticipated with a systemic, value-laden concept like sustainability, it was difficult to establish consensus on how, where and why to differentiate between themes. Each of the themes named by participants along with each theme's supporting ideas is listed in Box 1. 
Table 1. Sustainability themes derived by workshop participants during 'Conceptions of Sustainability: Mapping The Territory’ AaeE 2002 Professional Development Workshop

- Holism and society - Respecting and preserving community, cultural diversity, quality of life. Taking into account the societal setting and social implications of technological action. Being human centred.

- Appropriate design - Technology appropriate to the context. Serving social need, keep pace with social change. Affordable inventions. Using local resources and skills. Improves standards of living.

- Changing the development paradigm - Thinking about the future, globally. Systems focus. Alternative economic frameworks, redistribution of wealth. Recognising limits to consumption.

- Responsibility and balance - Taking responsibility for engineering impacts on environment and society, on a range of scales (eg. local, global, temporal). Meets or balances human needs and wants.

- Resource management/care - Preferential use of renewable rather than non-renewable resources. Conservation of non-renewables. Recycling resources. Not using up the environment.

- Safeguarding ecosystems - Avoid/regenerate damage, foster thriving ecosystems. Sensitivity to all physical elements (eg. air, water). Maintaining biodiversity. Consider non-human entities.

- Participatory processes - Ability to listen and appreciate a variety of viewpoints. Involve many disciplines, decision-makers, stakeholders in decision processes. Consult with the community.

- Business imperative - Coming up with affordable and/or profitable solutions. Wealth creation and wealth distribution. Economic payoff over the long term.

- Minimising impact - Minimising or mitigating environmental impacts. Considering whole of lifecycle impacts. Protecting society and social diversity.

- Philosophy - Spiritual needs. Cradle-to-grave thinking. Considering the process and the task. Involving values. Engineering as serving or leading.

- Integration - The integration of social, environmental and economic systems.

- Entropy - We can only minimise impacts. The second law of thermodynamics makes sustainability impossible.

The preceding section has demonstrated how two of the aims we nominated were addressed. The first aim was to engage the participating engineering academics in clarifying and making explicit their individual conceptions of environmental, social and economic sustainability. The initial workshop activity asked participants to respond to the questions 'What do you mean by environmental, social and economic sustainability?' and generated over 120 ideas. This represented an average of five distinct ideas per participant, and while some participants inevitably would have contributed greater numbers of ideas and some less, the number of distinct ideas that emerged demonstrated that some of the participants clarified and made explicit their individual conceptions of environmental, social and economic sustainability. 
The second aim of this investigation was to encourage the study participants to derive themes which represented the variation in conceptions of environmental, social and economic sustainability held by the group as a whole. Table 1 details the outcomes of the workshop facilitators' and participants' joint efforts at deriving representative themes. While the process of deriving themes and the outcomes were neither universally agreed nor uncontested amongst the group, this set of themes represents a reasonably democratic interpretation of how individual participants' conceptions of environmental, social and economic sustainability could be grouped into a dozen themes of sustainable engineering.

The third aim of this investigation was to create an opportunity to speculate on the actions for sustainability that might be embodied or implicit in each theme. In the next section, we return to the initial subdivision of the concept, sustainability into the subordinate concepts, environmental, social and economic sustainability and use this subdivision as a framework to interpret the actions that may be associated with the themes listed in Box 1. We then speculate on some of the assumptions that may underpin these themes and actions.

\section{Discussion}

\subsection{Themes and actions for sustainability}

The themes presented in Box 1 provide insights into the range of different actions individual academics might advocate for more sustainable engineering. Three of the themes were explicitly named as actions and what was assumed necessary to the implementation of the theme was broadly evident in each of these themes' headings. For 
example, 'changing the development paradigm' headed a group of ideas concerned with long term, broad scale, and/or systemic thinking in concert with using alternative economic frameworks, redistribution of wealth and/or recognising limits to consumption. As such, the ideas that supported the heading 'changing the development paradigm' represented different kinds of actions that engineers might engage in or support to achieve the action nominated in the theme's heading. The other themes headed by broad action statements were 'safeguarding ecosystems', and 'minimising impacts'. The remaining themes were named more as specific outcomes, and the actions necessary to achieve each outcome were to be found in the ideas the workshop participants had clustered under each thematic heading. For example, the theme 'resource management/care' encapsulated ideas like preferential use of renewable resources and recycling of resources. Another theme, 'business imperative', headed a group of ideas that included actions like 'coming up with affordable and/or profitable solutions', 'wealth creation and distribution' and 'economic pay-off over the long term'. The process of grouping ideas related to environmental, social and economic sustainability, and of deriving themes, demonstrated that there was both a broad range and substantial variation in the ways that participating engineering academics envisioned sustainability being actioned.

In the introduction to this paper, we provided evidence from the 2002 Delft conference on Sustainability in Engineering that there was a substantial variation in the way that engineering academics construct and deliver engineering courses focused on sustainability, and we referred to Constructivist educational theory that establishes a 
relationship between teachers' approach to teaching and prior conceptions of subject matter. Based on these, we suggested that inquiring into engineering academics' perceptions of necessary action for sustainability could provide insights into the range of specific actions that engineering academics might advocate while teaching engineering students how to incorporate and enact sustainability in their work as professional engineers. What is evident from Box 1 is that, amongst the 23 academics who participated in this study, there is an extensive range of actions and outcomes these academics associate with sustainability. Further, some of the actions described by participating academics may be difficult to reconcile. For example, the actions 'consider non-human entities' and 'maintaining biodiversity' would be seen by some sustainability commentators (eg. Ref [25]) as in direct conflict with 'being human centred'. The action 'economic pay-off over the long term' may be difficult to achieve alongside actions like 'redistribution of wealth' and 'affordable inventions'. So we observe both variation and potential incompatibility among some actions for sustainability. Does this mean that sustainability is just too conflicting and contradictory to attempt to teach?

\subsection{Utilizing variation for teaching and learning}

Faced with the wide range of potential actions for sustainability described by participants, and the difficulties associated with reconciling possibly incompatible actions, further analysis is required if the outcomes of this study are to move beyond documentation and toward utility. Moving beyond documentation requires some sense or statement of what might be a useful research outcome from this particular line of inquiry. 
This paper is based on three assertions:

1. the actions required to implement sustainability in the engineering context are contested;

2. what engineering academics already know, think and feel about actions for sustainability will influence the approach they take in teaching undergraduate students sustainable engineering; and

3. sustainability is necessarily and justifiably a variable concept.

Based on these three assertions, a useful outcome from this research would be some means of communicating, reflecting on and/or discussing this variation in actions for sustainability. Specifically, there would be utility in creating models that allowed engineering academics and their students to consider and discuss:

- the nature of variation in proposed actions for sustainability;

- the genesis of this variation; and

- the implications of these different conceptions and actions for teaching, learning and enacting sustainability in the engineering context.

In the next section, we allocate the themes generated during the study to the subordinate concepts that were initially used as prompts (environmental, social and economic sustainability). In the section following, we use this allocation of themes, and three related theoretical frameworks as a basis upon which to interpret and speculate on the values and assumptions that might have underpinned the observed variation in actions for sustainability described by engineering academics who participated in this study. 


\subsection{Structuring themes of environmental, social and economic sustainability}

In order to render the results of our study more useful, we integrated the findings (detailed in Box 1) with the conceptualisation of sustainability as three subordinate concepts (depicted in Figure 1) using an interpretive approach described by Sandberg [26]. We used Sandberg's phenomenographic orientation to allocate each theme from Box 1 to the three subordinate sustainability concepts, such as environmental, social and economic sustainability.

Sandberg's phenomenographic orientation is a mindset which can be adopted by researchers in interpreting qualitative research data. It requires the researcher to:

1. Maintain an orientation to the phenomena (remain open-minded and focused on themes of sustainability as they were described by the participants).

2. Maintain a describing orientation (have the intention of understanding how themes of sustainability were described, rather than why they were described that way).

3. Horizontalise all phenomena (treat all themes of sustainability and founding ideas as equally important) and

4. Maintain a focus on the content (what was included in each theme) rather than the structure (how disparate elements were linked in individual themes).

We adopted Sandberg's method to ask the following question of each theme and its supporting ideas: 'Which subordinate concept does this theme address?'. The results appear. 


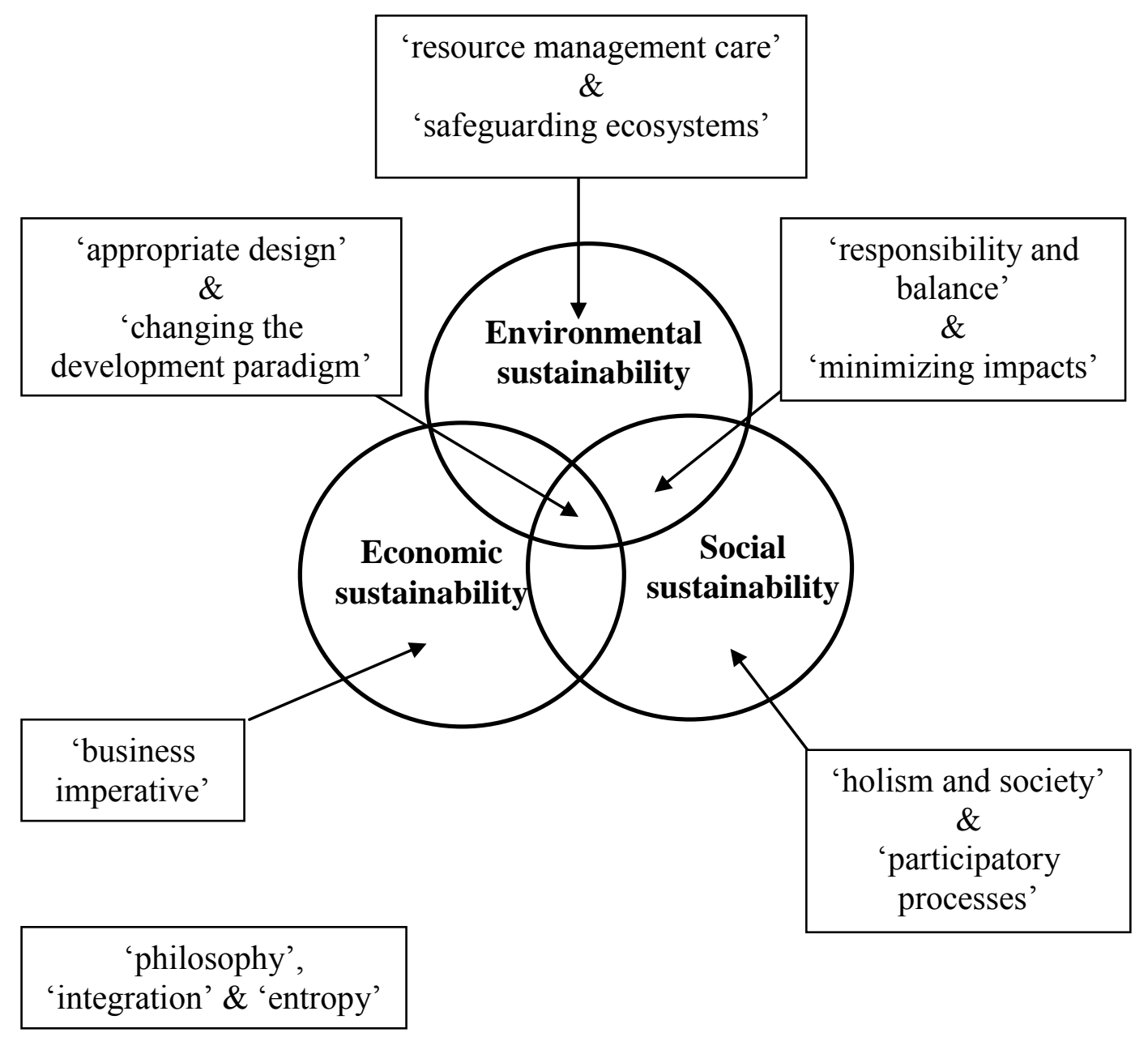

Figure 2. Allocation of themes to spheres of environmental, social and economic sustainability

Figure 2 shows the allocation of themes to environmental, social and economic sustainability. In Figure 2, two themes are depicted as largely related to environmental sustainability alone. They are 'resource management care' and 'safeguarding ecosystems'. Both of these themes appeared to be closely focused on the maintenance or responsible utilization of ecosystem products and services. Two themes were allocated to the zone of overlap between environmental and social sustainability. These themes were 
'responsibility and balance', which referred to the intersecting needs to take responsibility for and manage engineering impacts on both the environment and society, and 'minimizing impacts', which advocated the need to minimize impacts on society and environment. 'Holism and society' was heavily focused on taking account of, respecting and preserving social structures and was allocated to social sustainability alone. As was 'participatory processes', which advocated consultative and inclusive approaches to decision making. 'Business imperative' was allocated to economic sustainability as this theme had a strong focus on the profit motive, and wealth distribution and creation. We placed two themes at the intersection of all three sustainability subordinate concepts; 'appropriate design' and 'changing the development paradigm'. Both of these themes were based on ideas that mandated simultaneous action in the spheres of environment, society and economics. Appropriate design was focused on the conception and creation of affordable technology appropriate to its social context and purpose, and to its broader environmental context in terms of use of resources. Changing the development paradigm advocated a mix of long term, broad scale considerations and objectives. These ranged from taking a systems perspective, through alternative economic frameworks and goals, to recognize limits to consumption.

During our interpretation of the themes, three themes emerged that did not fit comfortably into the framework shown in Figure 2. These themes were 'philosophy', 'integration' and 'entropy'. It is possible to view these themes as a sustainability mindset, an overarching principle and as a caution, respectively. Alternately, these themes may simply not fit into the conceptual framework we used to structure themes. 
This second point would suggest, unsurprisingly, that the framework or subdivision of the broad concept, sustainability into three subordinate concept is not necessarily adequate to capture and structure all ideas and actions that might be pertinent to enacting sustainable engineering. We find this unsurprising because our experiences of trialing a variety of means for simplifying or subdividing the concept, sustainability have demonstrated that this complex, value-laden concept really warrants a multi-metaphor or multi-model approach (as suggested in Ref [10] [23]). As such, we offer the model at Figure 2 as one example or perspective on simplifying and reflecting on sustainability. The essence of this point is that it suggests engineering academics who might use the framework should also critically reflect on its capacity, or lack thereof, to represent actions for sustainability.

\subsection{Speculating on assumptions}

Having allocated themes to an organizing structure (Figure 2) based on the study's initial prompt questions, we evolved the research by speculating on what assumptions might support the observed variation in conceptions and actions for sustainability. In order to facilitate informed questioning and reflection in engineering students and their academics, we needed ways to simplify, structure and characterize the observed variation. In this section, we identify and describe theoretical frameworks with significant standing in their disciplines, as organizing structures. These frameworks offer utility for teasing out elements of both what is proposed (specific actions), and why it is proposed (values and assumptions). 
To further explore the observed variation, we employed theoretical frameworks related to environmental, social and economic sustainability. The first framework described variation in assumptions about purposes of environment and environmental resources, the second focused on human needs and motivation, and the third was about economic objectives and mechanisms. We detail each framework in the coming section. These frameworks are neither definitive nor singular, but rather serve as examples of how various disciplinary theories or philosophies might be applied to findings like those in Box 1 as means for interpreting the assumptions or values that may underpin different conceptions of sustainability.

\section{Environmental sustainability}

One way of interpreting the variation in the themes allocated to the environmental sphere in Figure 2 would be as founded on different views of environment and its purpose. Two such views are termed as 'anthropocentrism' and 'ecocentrism'. An anthropocentric view of environment frames environment in terms of its utility to humans, and the central view is of environment as a provider of products and services for the maintenance or improvement of human existence. This anthropocentric view of environment pervades the documentation of engineering professional bodies [27] [28] and has been described in sectors of the broader community [29] but meets some resistance in the sustainability literature [7] [25]. The ecocentric view frames environment as either having an intrinsic value independent of its utility to humans, or as fragile in its complexity. The second view is also seen by some as enlightened self-interest because, while this version of ecocentrism seeks to protect and preserve ecosystems, the motivation for doing so may be 
anthropocentric (eg. desire to maintain ecological health for the continued availability of resources).

Returning to the environmental themes depicted in Figure 2, we would contend that the anthropocentric and ecocentric views correspond particularly with the workshop themes 'resource management/care' and 'safeguarding ecosystems', respectively. We interpret the resource management/care theme as founded on anthropocentric drivers because the actions and ideas supporting this theme primarily focus on managing or conserving for ongoing human utility. The safeguarding ecosystems theme, however, appears to resonate more with an ecocentric view of environment. The actions and ideas that support this theme take a broader view of stewardship in that the duty of care is extended to non-human entities, biodiversity and ecosystem health.

This framework has potential utility in fostering and shaping discussion and debate amongst engineering educators and their students on their assumptions about the nature and purpose of environment, and how these assumptions might influence the practice of environmentally sustainable engineering. Subdividing into anthropocentric and ecocentric views of environment is not the only means of interpreting the themes' underpinning assumptions, and scholarly discussion and debate around this particular subdivision has been addressed in a variety of different dialogues and disciplines (eg. perceptions of environmental risk [29]; theology [30]; sustainability philosophy [25]). While the subdivision into ecocentrism and anthropocentrism offers many interesting avenues for scholarly discussion and debate, the immediate utility of raising this divide is 
as a means of structuring and reflecting on the range of different actions that engineering educators may advocate to their students as actions for environmental sustainability. Specifically, reflection on such a subdivision would offer an opportunity for academics and their students to consider what assumptions about the nature and purpose of environment might be embodied or enacted by different actions directed at environmental sustainability.

Before enlarging on the potential utility of this subdivision for teaching and learning sustainable engineering, we describe frameworks for interpreting the themes allocated to social and sustainability.

\section{Social sustainability}

In interpreting some of the assumptions that may underpin themes allocated to the social sphere in Figure 2, we consulted the literature on human need and motivation. It is interesting to consider the social sustainability themes derived during the workshop through the lens of Maslow's hierarchy of needs [31]. The detail of Maslow's hierarchy has been described as 'impressionistic, rather than conceptually rigorous', however, most critics acknowledge the enduring value of Maslow's general thesis [32].Viewing the themes through the lens of Maslow's hierarchy suggests that different social sustainability themes may be founded on different views of the duty of care engineers have for the societies within which, and for which, they work. 
Maslow was a psychologist who investigated and described a generic and additive hierarchy of human needs. The hierarchy (depicted on the left in Table 1), began with basic physiological needs for food, drink and thermal stasis, and moved successively through the needs for safety from physical harm, fear or threat; the need for love, enfranchisement and belonging; the need for the esteem of self and others; and ultimately, the need for self-actualisation in the form of fulfillment of personal potential [31]. Maslow held that humans would be most strongly oriented toward satisfying the subordinate needs in the hierarchy, before turning their efforts and attention to needs higher up the hierarchy. In the context of engineering educators' conceptions of sustainability, Maslow's hierarchy provides a means of differentiating between the needs addressed by the actions for social sustainability nominated by participating academics. We would suggest that the existence and nature of variation in the themes allocated to the social sustainability sphere in Figure 2 could be attributed to participating academics' assumptions about serving society. It would appear that these assumptions aligned with different parts of Maslow's hierarchy (i.e. different types of human need).

On the right side of Table 1, we list examples of themes or actions for social sustainability that were nominated by participants, and that correspond with the human needs described by Maslow. We merged the first two needs nominated by Maslow as both were expressed by him as fundamentals for human survival and, as Maslow pointed out, the absolute and chronic lack of these fundamentals tends to be confined to the unfortunate few in the relatively stable Western contexts within which his work and this study took place. As such, the examples in Table 1 corresponding with the first and 
second levels of need could be interpreted as satisfying either or both of these types of needs. The group of examples corresponding with the first two levels of Maslow's hierarchy can broadly be described as themes or actions aimed at protecting society and individuals in society from harm associated with degraded physical environment (taking responsibility for impacts on environment), unsatisfied basic needs (serving social needs) or depletion of access to resources and services (preserving quality of life). Perhaps the most eloquent example of an engineering academic addressing this level of need came out of the interview study we reported elsewhere [23], we include the quote in Table 1 to further illustrate a conception of social sustainability that focuses closely on physical needs.

The third level of need described by Maslow was a need for belonging, love and enfranchisement. In Box 1, we suggested that one of the actions supporting the theme holism and society demonstrated a duty of care that addressed the human need for belonging, love and enfranchisement. That action was 'preserving community and cultural diversity'. Maslow explained that a pre-condition of belonging was the existence of cohesive and distinct groups in society, as such the preservation of community and cultural diversity provides opportunities for individuals to be enfranchised and to belong.

The fourth level of Maslow's hierarchy was a need for self-esteem and for the esteem of others. One of the themes developed during the study was that of participatory processes, and we allocated this theme to the sphere of social sustainability (Figure 2). Two of the actions supporting the participatory processes theme were consult with the community, 
and listen and appreciate a variety of viewpoints. These two actions appear to address the need for the esteem of others in that implementing these actions in engineering decisions would demonstrate esteem for others in the form of respect for the viewpoint, priorities and values of the members of the community invited to participate in such decision processes.

None of the themes or actions described during the study appeared to address the need for self-actualisation. Maslow specified self-actualisation and the fulfillment of personal potential as the ultimate human need that would be pursued by those who had reasonably satisfied needs lower in the hierarchy. The themes and actions emerging from the study did not focus on or advocate support for individuals in the quest to fulfill individual potential. The quote we have used to illustrate such a conception of social sustainability is "providing individuals with the wherewithal to realise their true potential" and comes from an interview study with engineering academics described elsewhere [23].

Table 2 . Maslow's Hierarchy of Needs [31] aligned with various workshop themes or actions for social sustainability

\begin{tabular}{|c|c|}
\hline Maslow's Hierarchy of Needs & Theme or action for social sustainability \\
\hline $\begin{array}{l}\text { 1. physiological needs } \\
\text { (food, drink, thermal stasis) } \\
\qquad \& \\
\text { 2. safety needs } \\
\text { (safety from physical harm, fear, } \\
\text { threat) }\end{array}$ & 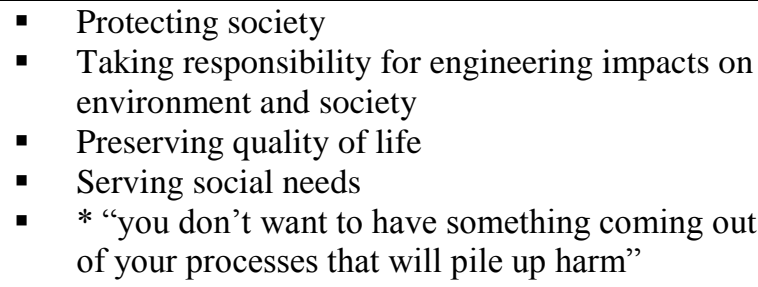 \\
\hline $\begin{array}{l}\text { 3. belonging needs } \\
\text { (belonging, love, enfranchisement) }\end{array}$ & - $\quad$ Preserving community, cultural diversity \\
\hline $\begin{array}{l}\text { 4. esteem needs } \\
\text { (self-esteem, esteem of others) }\end{array}$ & $\begin{array}{ll}\text { - } & \text { Consult with the community } \\
\text { - } & \text { Listen and appreciate variety of viewpoints }\end{array}$ \\
\hline
\end{tabular}




\begin{tabular}{|l|l|}
\hline $\begin{array}{l}\text { 5. self-actualisation needs } \\
\text { (fulfillment of potential) }\end{array}$ & $\begin{array}{l}* \text { "providing individuals with the wherewithall } \\
\text { to realise their true potential" }\end{array}$ \\
\hline$*$ These quotes are drawn from an earlier study reported in Carew and Mitchell (in press). \\
\hline
\end{tabular}

Our reason for interpreting the themes allocated to the social sustainability sphere through Maslow's hierarchy of needs was to suggest that different views of social sustainability might be understood to rest on different assumptions about the engineer's responsibility or duty of care for the societies within which they work, and for the individuals who make up those societies. For an engineer who sought to satisfy or serve needs lower down the hierarchy, a primary focus would be the provision of resources, consumer goods, and technologies that protected or promoted human health and safety. In comparison, an engineer seeking to support realisation of belonging, esteem or selfactualisation would potentially need to take quite different professional actions. The themes derived during the study demonstrated that participating engineering academics may well have held a wide range of views on what kind of social needs engineers should or could aim to satisfy.

\subsubsection{Economic sustainability}

In constructing Figure 2, we allocated three themes to the economic sustainability sphere. They were as follows: 'business imperative', 'appropriate design' and 'changing the development paradigm'. The ideas that supported these three themes appeared to rest on a range of assumptions about economic objectives and mechanisms. To speculate on the assumptions supporting the observed variation, we now briefly review the mechanisms and outcomes associated with three different economic frameworks: neoclassical economics, ecological economics and Marxism. The coming framework descriptions are 
necessarily concise, but intended to convey in straightforward terms the distinctions between these economic stances that are most relevant to descriptions of economic sustainability observed during the study.

Since the industrial revolution and the rise of capitalism, many countries have adopted and enacted some form of neoclassical economic framework to manage national economies. These frameworks are often associated with privatisation of the production of goods and provision of services, and with relatively low levels of government regulation. Neoclassical economics tends to support the stratification of wealth, to promote relatively short planning horizons (eg. 1e4 years), and to foreground the profit motive while relying on market forces to affect the provision of goods and services and the distribution of wealth [33].

Engineering academics who participated in the study named a group of ideas as 'business imperative'. This theme appeared allied to a neoclassical economic stance given that it had a strong focus on the profit motive, and wealth creation and distribution. A principle assumption of neoclassical economics is that market forces, if allowed to operate freely, tend to address and remedy problems associated with the distribution of wealth [34]. As we discuss later, this assumption is seen by some economists as a major failing of this particular approach to the management and conceptualisation of how money works in society. If neoclassical economic assumptions do underpin the 'business imperative' theme of economic sustainability, then associated actions for promoting economic sustainability through engineering practice would likely focus on wealth creation for 
discrete entities (eg. companies) with the overall objective of contributing positively to measures of economic prosperity (eg. gross domestic product) under the assumption that growth in national economic prosperity would affect wealth distribution (eg. a trickledown effect) [33].

A second school of economic theory that may throw light on assumptions underpinning themes derived during the study, and that contrasts with the neoclassical stance, is Marxist economic theory and its associated social outcome, communism. The central objective of Marx's economic framework was the active redistribution of wealth and decision-making power with the aim of achieving greater economic equity for individuals in communist society [35]. Under this theoretical framework, the means of production were State owned and profits were used to provide universal and equitable access to goods, services and social infrastructure [36]. While the failings and eventual collapse of communism in what was the USSR have somewhat discredited this economic theory, elements of Marx's framework continue to influence economic management and public policy in many different guises (eg. socialism in China; high taxes and relatively generous social services in Scandinavian countries; high levels of unionisation in some Australian industry sectors). One of the themes depicted in the economic sustainability sphere in Figure 2 was 'changing the development paradigm' and one of its founding ideas was the redistribution of wealth. The redistribution of wealth resonates with Marxist economic theory's objective of promoting economic equity through the active, centralised and/or legislative redistribution of wealth. The relevance of this to sustainable engineering is that a conceptualisation of economic sustainability motivated 
primarily by the need for wealth redistribution would be associated with quite different actions on the part of professional engineers to one motivated by the generation of profit for a discrete entity.

A third framework, which was proposed in response to some of the perceived shortcomings of neoclassical economics, is called ecological economics. This economic framework has its genesis in the thinking of economist Georgescu-Roegan [37] and addresses three values that proponents suggest are in conflict under neoclassical economics: allocation (efficiency), distribution (justice), and scale (sustainability) [38]. Daly and Cobb [39] advocate a paradigm shift in economic thought that questions the fundamental assumption of economics that the pursuit of private gain (self-interest) in rational, and that action for the public good (other-regarding behavior) is irrational. In addressing this conflict of values, and the flawed assumption that self-inerest is an unassailably rational course of action, ecological economics advocates the valuation of goods and services that are often framed by neoclassical economic theory as 'externalities' and, as an extension of this, the acknowledgement of more complex motivations and interconnections between humans and the rest of nature [39]. Examples of externalities include ecosystem services, public goods, and social and environmental amenity.

The economic sustainability themes derived during our study included 'appropriate design' and 'changing the development paradigm'. Appropriate design rested in part on the idea that technologies designed by engineers should be appropriate to their broader 
environmental context particularly in terms of use of resources. Changing the development paradigm advocated the use of alternative economic frameworks and goals, and recognizing limits to consumption. These ideas accord with an ecological economics stance in that the use of alternative economic frameworks would potentially allow for the valuation of environmental goods that neoclassical economic theory either ignores (eg. limits to resources, indirect ecosystem services [38]), or frames as externalities (eg. local environmental amenity). Valuation of such environmental goods and services would necessarily impact on engineering decision processes and outcomes as the costs and benefits of different technological options could be quite different using an ecological economic approach to valuation, as opposed to the more usual neoclassical approach.

In the foregoing section, we introduced theories and frameworks relevant to environmental, social and economic sustainability. We explained these frameworks in broad terms and used them to speculate on some of the assumptions that might have underpinned the variation in engineering academics' conceptions of sustainability and actions for sustainability derived during the study. We also suggested ways the assumptions that correspond with each framework might influence the actions or outcomes of professional engineering activity. The following section builds on these ideas and describes how reflecting on variation in assumptions about environmental, social and economic sustainability might benefit teaching and learning sustainability in the undergraduate engineering context. 


\subsection{Exploring and capitalizing on variation in conception of sustainability}

In the early part of this chapter and elsewhere [23] we have argued that variation and conceptual contest over what constitutes sustainability are positive and necessary. We argued that active debate over the concept of sustainability has the potential to give voice to a range of different values sets; could broaden the range of starting points, processes and end points that a sustainable decision process might entail; and could promote the necessary flexibility that a concept like sustainability must cultivate if it is to continue to affect contextually appropriate and creative outcomes. From this perspective, the variation in conception of sustainability documented during the study represents a valuable resource for teaching and learning sustainable engineering in the undergraduate context. In order to capitalise on this diversity for positive teaching and learning outcomes it would be necessary to practice what Lemkowitz al[18] called 'intellectually responsible teaching of concepts with strong normative content'. According to these researchers, an important part of teaching concepts like sustainability is acknowledging and making explicit the values-based assumptions which inform different positions on or conceptions of the concept. For those academics charged with teaching sustainability in undergraduate engineering this would mean being conscious of and explicit with students about the assumptions that informed the positions on sustainability which the academics chose to include in the syllabus, and perhaps inviting students to explore alternative founding assumptions.

The theoretical frameworks we used in the preceding section to explain and discuss observed variation in how a group of engineering academics conceived of environmental, 
social and economic sustainability might be useful for assisting both students and academics in the process of clarifying sustainability assumptions, and the impact that assumptions might have on engineering decision-making. In the example of using these models to assist students to develop an appreciation of the place of values in sustainable engineering, students might be asked to consider how they would approach a design task (eg. design a wastewater treatment plant) given certain sustainability responsibilities (eg. the design process and outcome must be environmentally sustainable), and certain sustainability assumptions (eg. assume an ecocentric, long-term, and/or global perspective on environmental sustainability). Clearly students tasked with designing to such a brief would come up with a different design process and outcome to students asked to, for example, design an economically sustainable wastewater treatment plant that conformed with a short-term, profit-motivated conception of economic sustainability. Or, alternately, a plant that promoted social sustainability in the society it served, where social sustainability was seen in terms of Maslow's conception of the human need for belonging, love and enfranchisement, or the esteem of others. An important part of such an approach would be to encourage students to reflect on the priorities they identified and the processes they used in response to the dictated sustainability assumptions, and the impact of those priorities and processes on final design outcomes.

\section{Conclusions}

In this paper we demonstrated that there is substantial variation in the way that individual engineering academics conceived of environmental, social and economic sustainability. We documented an array of different sustainability themes and actions that were described by engineering academics who participated in a professional development 
workshop on mapping conceptions of sustainability, and proposed three theoretical frameworks to speculate on some of the founding assumptions that might have affected the observed diversity.

The research and synthesis in this paper would suggest that a significant part of the challenge for individual academics attempting to infuse concepts of sustainability into undergraduate coursework is to acknowledge that sustainability is a concept with both factual and values-based components, and hence should and does manifest in variable ways. This suggest that, rather than advocating specific tools, sets of actions or particular outcomes as 'sustainable', academics might develop approaches to teaching and learning which considered the role of values and assumptions in sustainable decision-making. Theoretical frameworks like those we described in the second part of this paper could support such teaching and learning; pedagogy aimed at engaging students' awareness of how and why a diversity of values, viewpoints and actions might assist them in developing as flexible, creative practitioners, with the capacity to enact sustainability in the diverse array of professional contexts their future working life may present.

\section{Acknowledgements}

We would like to thank the workshop participants for sharing their views on sustainability with us. 


\section{References}

[1] Wright TSA. Definitions and frameworks for environmental sustainability in higher education. International Journal of Sustainability in Higher Education 2002;3(3): 203-220.

[2] Harding R. Environmental Decision-making: the roles of scientists, engineers and the public. Sydney, Australia: The Federation Press, 1998.

[3] Engineers, Australia. Accreditation Criteria Summary. In: Bradley A, editor. Accreditation Management System Education Programs at the Level of Professional Engineer. Engineers, Australia, , 2005 Document number S02.

[4] Filho WL. Dealing with Misconceptions on the Concept of Sustainability. International Journal of Sustainability in Higher Education 2000; 1 (1): 9-19.

[5] Jacobs M. Sustainable Development as a Contested Concept. In: Dobson A, editor. Fairness and Futurity: Essays on Environmental Sustainability and Social Justice. Oxford, UK: Oxford University Press, 1999.

[6] AtKisson A. Sustainability is Dead - Long Live Sustainability: A Manifesto. Self-published, 2001.

[7] Gardener G. Invoking the Spirit: Religion and Spirituality in the Quest for a Sustainable World. Worldwatch Paper 164, 2002.

[8] Gough S. Increasing the value of the environment: a 'real options' metaphor for learning. Environmental Education Research 2002; 8(1): 61-71.

[9] Robèrt K-H, Schmidt-Bleek B, Aloisi De Larderel J, Basile G, Jansen JL, Kuehr R, Price Thomas P, Suzuki M, Hawken P \& Wackernagel M. Strategic sustainable development - selection, design and synergies of applied tools. Journal of Cleaner Production 2002;10(3): 197-214.

[10] Scott W. Sustainability and Learning: What Role for the Curriculum? University of Bath Inaugural Lecture, 2002. Available at http://www.bath.ac.uk/cree/home.htm.

[11] Carew AL and Mitchell CA. Characterising Undergraduate Engineering Students' Understanding of Sustainability. European Journal of Engineering Education 2002;27(4): 349-361.

[12] Funtowicz S and Ravetz J. Science for the post-normal age. Futures 1993;25(7): 739-755.

[13] Crofton F. Sustaining Engineering: Rationale and directions for preparing engineers for sustainable development. Doctoral dissertation at Simon Fraser University, Burnaby, Canada 1995.

[14] Crofton F. Educating for sustainability: opportunities in undergraduate engineering. Journal of Cleaner Production 2000;8: 397-405.

[15] Boyle C. Education, Sustainability and Cleaner Production. Journal of Cleaner Production 1999;7: 8387.

[16] Clift, R. (1998) Engineering for the Environment: The New Model Engineer and her Role, Transactions of the Institution for Chemical Engineering, 76 (B), 151-160.

[17] Prosser, M. and Trigwell, K. (1999) Understanding Learning and Teaching: The Experience in Higher Education. The Society for Research into Higher Education and Open University Press. Buckingham, United Kingdom. 
Engineering Educators' Conceptions of Sustainability

[18] Lemkowitz, S. M., Korevaar, G., Bonnet, J. A. B. A. F. and Lameris, G. H. (2002) Intellectually Responsible Teaching of Subjects with Strong Normative Content, Like 'Sustainability' at Universities. Proceedings of Engineering Education in Sustainable Development Conference, (p. 55). October 2002, Delft University, The Netherlands.

[19] Wells, P. (2002) Towards a Philosophy of Sustainable Engineering. Proceedings of Engineering Education in Sustainable Development Conference, (p. 48). October 2002, Delft University, The Netherlands.

[20] WCED (1987) Our Common Future. World Commission on Environment and Development. Oxford University Press, Oxford.

[21] Clift, R. (1995) The Challenge for Manufacturing. In Engineering for Sustainable Development, J. McQuaid (ed.), The Royal Academy of Engineering, London.

[22] Mitchell, C. (2000) Integrating Sustainability in Chemical Engineering Practice and Education: concentricity and its consequences, Transactions of the Institution for Chemical Engineering, 78(B), 237-242.

[23] Carew, A. L. and Mitchell, C. A. (in press) Metaphors used by some Australian engineering academics for understanding and explaining sustainability Environmental Education Research.

[24] Brassard, M. (1989) The Memory Jogger. Methuen, Massachusetts.

[25] Nieto, C.C. (1999) Toward a Holistic Approach to the Ideal of Sustainability, Society for Philosophy and Technology, 2, 2, 41-48.

[26] Sandberg, J. (1994) Human Competence at Work: an interpretative approach. Doctoral dissertation, University of Göteborg, Sweden.

[27] IEAust (1994) Code of Ethics. The Institution of Engineers, Australia. Canberra, Australia.

[28] WFEO (1999) Strategic Plan for the New Millennium. World Federation of Engineering Organisations.

[29] Adams, J. and Thompson, M. (2002) Taking Account of Societal Concerns about Risk: Framing the Problem. A report for the UK Health and Safety Executive. May 2002.

[30] Cywinski, Z. (2001) 'Current Philosophy of Sustainability in Civil Engineering', Journal of Professional Issues in Engineering Education and Practice, January 2001, 12-16.

[31] Maslow, A. H. (1987) Motivation and Personality. Longman, New York.

[32] Costanza, R., Daly, H. E. and Bartholomew, J. A. (1991) Goals, Agenda, and Policy Recommendations for Ecological Economics. Chapter one in Ecological Economics R. Costanza (ed.), Columbia University Press, New York.

[33] Hawken, P., Lovins. A, and Lovins, L. H (2000) Natural Capitalism: Creating the Next Industrial Revolution, Back Bay Books, Boston.

[34] Marx, K. (1992) Capital: A Critique of Political Economy (reprint edition). Penguin Books, New York.

[35] Marx, K. and Engels, F. (1998) The Communist Manifesto (reprint edition). Signet Classics, London. 
Engineering Educators' Conceptions of Sustainability

[36] Mayumi, K. (2001) The Origins of Ecological Economics. Routledge, London.

[37] Daley, H. E. (1991) Elements of Environmental Macroeconomics. Chapter one in Ecological Economics R. Costanza (ed.), Columbia University Press, New York. 